\title{
Effect of crude degummed canola oil and ad libitum grazing on plasma metabolites of primiparous Holstein-Friesian cows in a pasture-based system
}

John R Otto ${ }^{1+}$, Bunmi S Malau-Aduli ${ }^{2+}$, Razaq O Balogun ${ }^{3+}$, Peter Nish $^{4+}$ and Aduli E O Malau-Aduli ${ }^{1,5^{*}}$

\begin{abstract}
Background: The supplementation of fat to lactating dairy cows has long been used as a management tool to increase dietary energy density for improving cow production, reproduction and to alleviate negative energy balance. Attempts have been made to investigate the effect of canola meal on plasma metabolites in lactating cows, but the results have been diverse and inconsistent. To our current knowledge, there is a dearth of published information on the utilization of Crude Degummed Canola Oil (CDCO) in pasture-based dairy systems. Therefore, the objective of this study was to investigate the changes in plasma metabolite profiles of pasture-based, primiparous, Holstein-Friesian cows supplemented with varying dietary levels of CDCO for eight weeks. The study tested the hypothesis that feeding grazing primiparous Holstein-Friesian cows for eight weeks with incremental levels of CDCO supplement will decrease plasma non-esterified fatty acids (NEFA) and $\beta$-hydroxybutyrate (BHBA), but increase plasma cholesterol and glucose metabolites.
\end{abstract}

Results: Twenty lactating primiparous Holstein-Friesian cows 40 days in milk were randomly allotted into four treatment groups that consisted of a wheat-based, pelleted basal diet with no supplemental CDCO (control), basal diet with CDCO added at $25 \mathrm{ml} / \mathrm{kgDM}$ (DM; dry matter) (low), $35 \mathrm{ml} / \mathrm{kgDM}$ (medium) and $50 \mathrm{ml} / \mathrm{kgDM}$ (high) in an eight-week feeding trial, after two weeks of adjustment. Treatment influenced BHBA but had no effect on plasma NEFA, cholesterol and glucose metabolite profiles $(P>0.05)$. However, week of supplementation had a significant effect $(P<0.05)$ on BHBA, NEFA and glucose concentrations.

Conclusions: We concluded that with the exception of BHBA, CDCO at current levels of supplementation does not alter the plasma metabolite profiles of grazing primiparous cows. The lack of significant differences across treatments seems to indicate that higher levels of CDCO than the current levels used in this study, are probably needed. Furthermore, the duration of supplementation with CDCO had a greater impact on plasma metabolites than the levels of supplementation. Our findings also suggest that primiparous cows grazing high quality pastures during spring have sufficient energy intakes to prevent negative energy balance at 40 days in milk without the need for added fat supplements.

Keywords: Primiparous Holstein-Friesians, Crude degummed canola oil, Supplement, Plasma metabolites

\footnotetext{
* Correspondence: Aduli.MalauAduli@utas.edu.au

${ }^{\dagger}$ Equal contributors

${ }^{1}$ Animal Science and Genetics, Tasmanian Institute of Agriculture, School of Land and Food, Faculty of Science, Engineering \& Technology, University of Tasmania, Private Bag 54, Hobart, TAS 7001, Australia

${ }^{5}$ Veterinary and Biomedical Sciences, College of Public Health, Medical and Veterinary Sciences, Division of Tropical Health and Medicine, James Cook University, Townsville, Queensland 4811, Australia

Full list of author information is available at the end of the article
} 


\section{Background}

Primiparous Holstein-Friesian cows are the most energychallenged animals on a typical pasture-based dairy farm, because in such a herd, they are at the bottom of the social hierarchy [1]. This is because primiparous cows are always the last to be milked and by implication, arrive last in the paddock, thus potentially reducing grazing time. This pattern, coupled with incidences of bullying and competition for grass in the paddock, contributes to low feed intake. Given that most first-time calvers are still heifers that are not fully grown at the time of calving ( $85-90 \%$ of mature cow size), they have to regain post-partum weight loss (up to $100 \mathrm{~kg}$ of pre-calving weight) and also continue to grow and produce milk [1]. Therefore, primiparous cows tend to suffer more negative energy balance (NEBAL) than all the animals in the herd. With all these pressures and mating occurring fairly soon after calving, it is no wonder that they tend to have diminished milk production and reproduction performances.

Canola plant has been engineered to produce oil with greater concentrations of omega- 9 , omega- 6 and adequate omega-3 fatty acids. Metabolism of canola oil in the rumen is facilitated by rumen microorganisms, particularly bacteria and protozoa. Bacterial lipase hydrolyses the triacylglycerols and phospholipids in the consumed dietary oil. Once the fatty acids are liberated from their ester linkages, the end products (glycerol and NEFA) are utilised in the biohydrogenation process. Biohydrogenation is an extensive microbial process that involves the addition of hydrogen molecules to unsaturated free fatty acids concentrated in the rumen. During biohydrogenation, unsaturated fatty acids (linoleic and alpha-linolenic acids) are extensively hydrogenated to form saturated fatty acids (stearic acid 18:0 and palmitic acid 16:0). The biohydrogenation of linoleic acid to stearic acid is demonstrated in Figure 1 [2].

Following biohydrogenation, the saturated and unsaturated fatty acids that escape this process are subsequently absorbed in the small intestine. As a result of rumen biohydrogenation, approximately $85 \%$ and $15 \%$ saturated and free fatty acids respectively, are transported into the small intestine and this process illustrates the efficiency of rumen

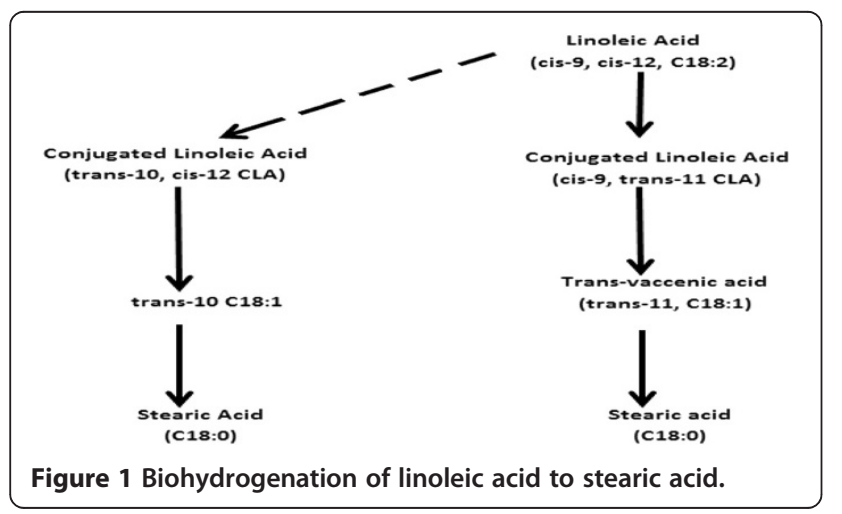

microbes. Rumen biohydrogenation is the major factor affecting the delivery of fat in the small intestine and subsequent transportation in the blood of ruminants. Fat consumption by cows leads to the productions of volatile fatty acids (mainly acetate, butyrate and propionate). These volatile fatty acids are the precursors for the production of glucose, carbohydrates and fats.

The energy status of a cow is mostly reflected by its plasma non-esterified fatty acids (NEFA) and $\beta$ hydroxybutyrate (BHBA) profiles [3-6]. A reduction in the level of plasma glucose can also be used as an indicator of NEBAL in cows. Previous studies have suggested that NEFA concentration should be less than $0.2 \mathrm{mmol}$ for normal cows [7]. However, values ranging from 0.5 to $0.7 \mathrm{mmol}$ postpartum are indicative of NEBAL [8]. To prevent NEBAL in lactating cows, supplementation with limited amount of dietary fat in a pasture setting to boost postpartum energy intake has been of increasing research interest [9]. The effect of dietary fat supplements on plasma metabolites in dairy cows has been inconsistent and highly variable in the published literature. For instance, some studies found increased glucose, NEFA, BHBA and cholesterol [10-13], while others found no change [14-17] or had inconsistent results [18]. This suggests that further studies in different production systems are required to enable informed choices and tailored decisions when feeding lactating cows with specific dietary fat supplements, hence the justification for our study in a typical Australian pasture-based dairy production system.

The Australian dairy industry has increasing interest in crude degummed canola oil (CDCO) because of its ease of local availability and affordability. However, limited information currently exists in the published literature on the effect of $\mathrm{CDCO}$ on plasma metabolites. Therefore, this study intends to fill this knowledge gap by investigating the effect of dietary inclusion of $\mathrm{CDCO}$ at incremental levels for eight weeks on the plasma metabolite profiles of primiparous Holstein-Friesian cows in a pasture-based system. We hypothesized that feeding grazing primiparous Holstein-Friesian cows for eight weeks with incremental levels of $C D C O$ supplement will decrease plasma NEFA and BHBA, but increase cholesterol and glucose levels.

\section{Results}

Effect of CDCO level and week of supplementation on plasma metabolites

Crude Degummed Canola Oil supplementation level had no significant differences on plasma NEFA compared to the control treatment. However, week of supplementation had a highly significant effect $(\mathrm{P}<0.05)$ on plasma NEFA. Also, no significant interaction effect of treatment by week was detected on plasma NEFA $(\mathrm{P}>0.05$; Table 1$)$. 
Plasma BHBA was significantly affected by both treatment $(\mathrm{P}<0.0241)$ and week of supplementation $(\mathrm{P}<0.05)$, although their interaction (treatment by week), was not significant $(\mathrm{P}>0.05$; Table 1). However, plasma BHBA concentration in cows receiving the high treatment was similar to that of cows in the control group ( $0.5 \pm 0.0$ vs $0.5 \pm 0.0 \mathrm{mmol})$, but differed from those of cows receiving low $(0.4 \pm 0.0 \mathrm{mmol})$ and medium $(0.4 \pm 0.0 \mathrm{mmol})$ levels of CDCO (Table 2).

There were no significant $(\mathrm{P}>0.05)$ differences in the mean plasma cholesterol and glucose concentrations of supplemented and unsupplemented cows. However, week of supplementation influenced glucose significantly $(\mathrm{P}<0.05)$ as the level fell down in Week 2 , but cholesterol was not affected $(\mathrm{P}>0.05$; Table 1$)$.

\section{Correlations between traits}

Table 3 shows that there were highly significant correlations $(P<0.001)$ between BHBA and NEFA $(-0.32)$, cholesterol (0.24) and glucose (0.34). All other correlations were not significant $(\mathrm{P}>0.05)$.

\section{Weekly trends in plasma metabolites of supplemented and unsupplemented cows}

The weekly concentration trends of NEFA (Figure 2), cholesterol (Figure 3) and glucose (Figure 4) were similar across treatments and the control groups. However, the weekly BHBA trends for cows in the high group were higher compared to the medium, low and control groups (Figure 5).

\section{Discussion}

Enormous remobilization of NEFA from adipose tissues postpartum occurs in high merit cows as a sign of transition from gestation to milk production [8]. However, high concentrations of NEFA in the blood can be toxic and compromise the production and reproduction performances of cows [19-22]. Plasma NEFA can provide the body tissues with energy when not in excessive quantities. However, when the animal is suffering from negative energy balance, excessive amounts of NEFA in the blood can be toxic to

Table 1 Fixed and interaction effects (p-values) of CDCO treatment and week of supplementation on plasma metabolites

\begin{tabular}{lllll}
\hline Effect & \multicolumn{4}{l}{ Plasma metabolites } \\
\cline { 2 - 5 } & BHBA & Cholesterol & Glucose & NEFA \\
\hline TRT & $0.0241^{*}$ & $0.6681^{\mathrm{NS}}$ & $0.4143^{\mathrm{NS}}$ & $0.1314^{\mathrm{NS}}$ \\
Week & $0.0001^{* * *}$ & $0.9415^{\mathrm{NS}}$ & $0.0005^{* *}$ & $0.0001^{* *}$ \\
TRT Week & $0.6489^{\mathrm{NS}}$ & $0.9962^{\mathrm{NS}}$ & $0.2613^{\mathrm{NS}}$ & $0.8714^{\mathrm{NS}}$ \\
\hline
\end{tabular}

Level of significance: ${ }^{N S}$ not significant $(P>0.05)$, ${ }^{*}$ significant $(P<0.05)$, **highly significant $(P<0.01)$, ${ }^{* * *}$ very highly significant $(P<0.001) ; \beta$-hydroxybutyrate (BHBA, mmol), non-esterified fatty acid (NEFA, mmol), Cholesterol (mmol), Glucose (mmol); Crude degummed canola oil (CDCO).
Table 2 Least square means (LSM \pm S.E) of plasma metabolites as influenced by CDCO treatment and week of supplementation

\begin{tabular}{lllll}
\hline Effect & \multicolumn{4}{l}{ Plasma metabolites } \\
\cline { 2 - 5 } & BHBA & Cholesterol & Glucose & NEFA \\
\hline Control & $0.5 \pm 0.0^{\mathrm{a}}$ & $5.8 \pm 0.2$ & $3.9 \pm 0.1$ & $0.2 \pm 0.0$ \\
High & $0.5 \pm 0.0^{\mathrm{a}}$ & $5.6 \pm 0.3$ & $3.9 \pm 0.1$ & $0.2 \pm 0.0$ \\
Low & $0.4 \pm 0.0^{\mathrm{b}}$ & $5.3 \pm 0.3$ & $3.7 \pm 0.2$ & $0.1 \pm 0.0$ \\
Medium & $0.4 \pm 0.0^{\mathrm{b}}$ & $5.5 \pm 0.2$ & $3.9 \pm 0.1$ & $0.2 \pm 0.0$ \\
Week & & & & \\
0 & $0.4 \pm 0.0$ & $5.5 \pm 0.2$ & $4.1 \pm 0.1$ & $0.2 \pm 0.0$ \\
2 & $0.6 \pm 0.0$ & $5.6 \pm 0.2$ & $4.0 \pm 0.1$ & $0.1 \pm 0.0$ \\
3 & $0.4 \pm 0.0$ & $5.6 \pm 0.3$ & $3.8 \pm 0.1$ & $0.2 \pm 0.0$ \\
5 & $0.6 \pm 0.0$ & $5.5 \pm 0.3$ & $4.0 \pm 0.1$ & $0.1 \pm 0.0$ \\
7 & $0.4 \pm 0.0$ & $5.3 \pm 0.5$ & $3.5 \pm 0.2$ & $0.2 \pm 0.0$ \\
8 & $0.4 \pm 0.0$ & $5.7 \pm 0.4$ & $3.7 \pm 0.1$ & $0.1 \pm 0.0$ \\
\hline
\end{tabular}

Column means within a variable bearing different superscripts significantly differ $(\mathrm{P}<0.05)$; $\beta$-hydroxybutyrate $(\mathrm{BHBA}, \mathrm{mmol})$, non-esterified fatty acid (NEFA, mmol), Cholesterol (mmol), Glucose (mmol); Crude degummed canola oil (CDCO). Week 0, week before supplementation, week 2, second week of fat supplementation.

the animal. Most of the NEFA in the liver can be metabolised into triacylglycerols. Accumulated NEFA leads to excess triacylglycerols accumulating in the liver and the unutilised residual acetyl-CoA from the oxidation of fatty acids in the tricarboxylic acid cycle is converted into ketone bodies, such as acetone, acetoacetate and BHBA. The results of our current study found no significant effect of feeding CDCO on NEFA concentration in contrast to Andersen et al. [23] and Douglas et al. [24] who reported increases in NEFA. These previous studies utilized different forms and higher dosages of dietary fat sources which could explain the observed differences. The CDCO levels utilised in our study were tailored to avoid feeding greater than the $7 \%$ total fat allowed in the diets of grazing animals [9] because it can affect dry matter intake and ruminal fibre digestion [9]. Another explanation for the lack of observable differences between the supplemented and unsupplemented groups of animals in our study could be related to the metabolisable energy component of the CDCO which was very similar for both the control and basal

Table 3 Pearson's correlation coefficients between plasma metabolites

\begin{tabular}{lllll}
\hline Traits & BHBA & Cholesterol & Glucose & NEFA \\
\hline BHB(mmol) & & $0.24^{*}$ & $0.34^{* * *}$ & $-0.32^{* * *}$ \\
Cholesterol(mmol) & $0.24^{*}$ & & $0.25^{* *}$ & $-0.02^{\mathrm{NS}}$ \\
Glucose $(\mathrm{mmol})$ & $0.34^{* * *}$ & $0.25^{* *}$ & & $0.03^{\mathrm{NS}}$ \\
NEFA(mmol) & $-0.32^{* * *}$ & $-0.02^{\mathrm{NS}}$ & $0.03^{\mathrm{NS}}$ & \\
\hline
\end{tabular}

Level of significance: ${ }^{N S}$ not significant $(P>0.05)$, ${ }^{*}$ significant $(P<0.05)$, **highly significant $(P<0.01)$, ***very highly significant $(P<0.001) ; \beta$-hydroxybutyrate (BHBA), non-esterified fatty acid (NEFA). 


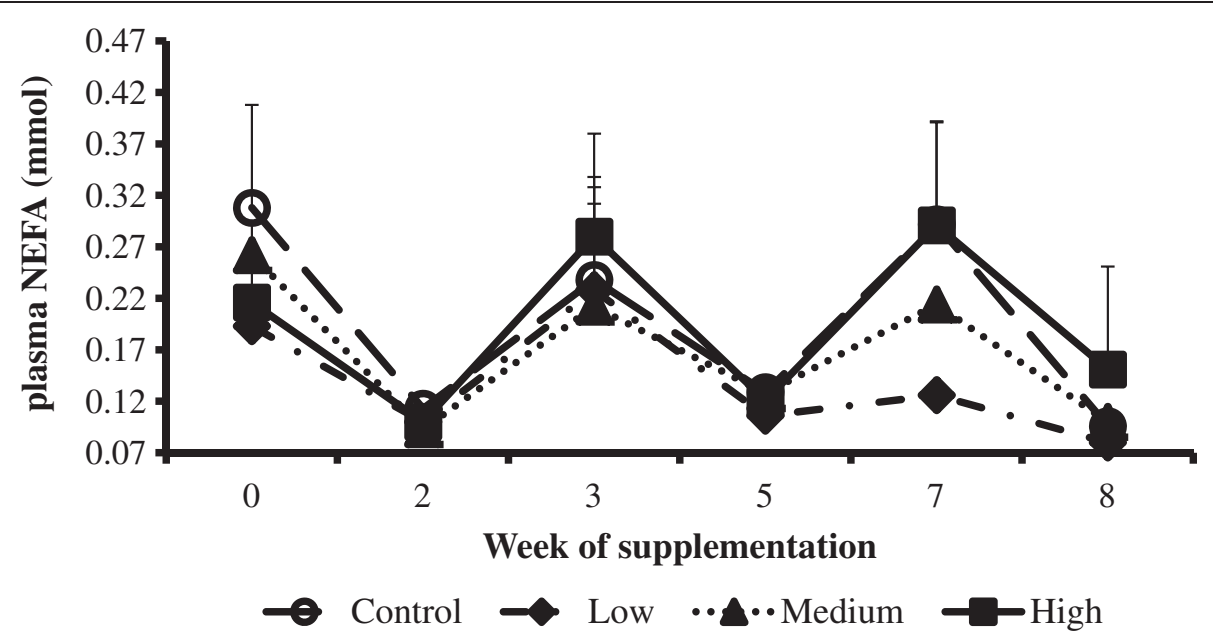

Figure 2 Interaction between CDCO supplementation level and week of supplementation on plasma concentrations of non-esterified fatty acids. Error bars ( \pm SEM). Each treatment group had five cows. Week 0, week before fat supplementation, week 1, when fat supplementation commenced.

diet (isocaloric). Secondly, the result also suggests that the ryegrass pastures that were grazed by the cows were of high quality and provided adequate energy to the postpartum cows to prevent massive adipose tissue remobilisation. The similarity across weeks and between treatment groups (average $0.2 \mathrm{mmol}$ ) in plasma NEFA suggests similar energy intake and utilisation. It has been suggested that three weeks pre-partum to three weeks post-partum is the most energy deficit period for high merit cows [25], but the cows in our study were already 40 DIM (days in milk) and might have well passed the critical energy deficit periods, hence the lack of observable treatment differences. It has also been reported that the level of plasma NEFA was greater in primiparous cows soon after calving [26], implying that fat supplementation studies on NEFA should be carried out during the early calving period [27].

Plasma BHBA is a product of NEFA that is converted into triacylglycerols in the liver $[28,29]$. In the present study, feeding CDCO significantly influenced plasma BHBA concentration where a slight, but significant increase in BHBA was observed as the level of CDCO increased from low to high (Table 2). Our results are in contrast with those of [30] who found that when rumen inert fat was fed to dairy cows, plasma BHBA decreased prepartum. This disparity could be linked to the differences in the physiological states of the experimental cows. In our study, the cows were only 40 days in milk

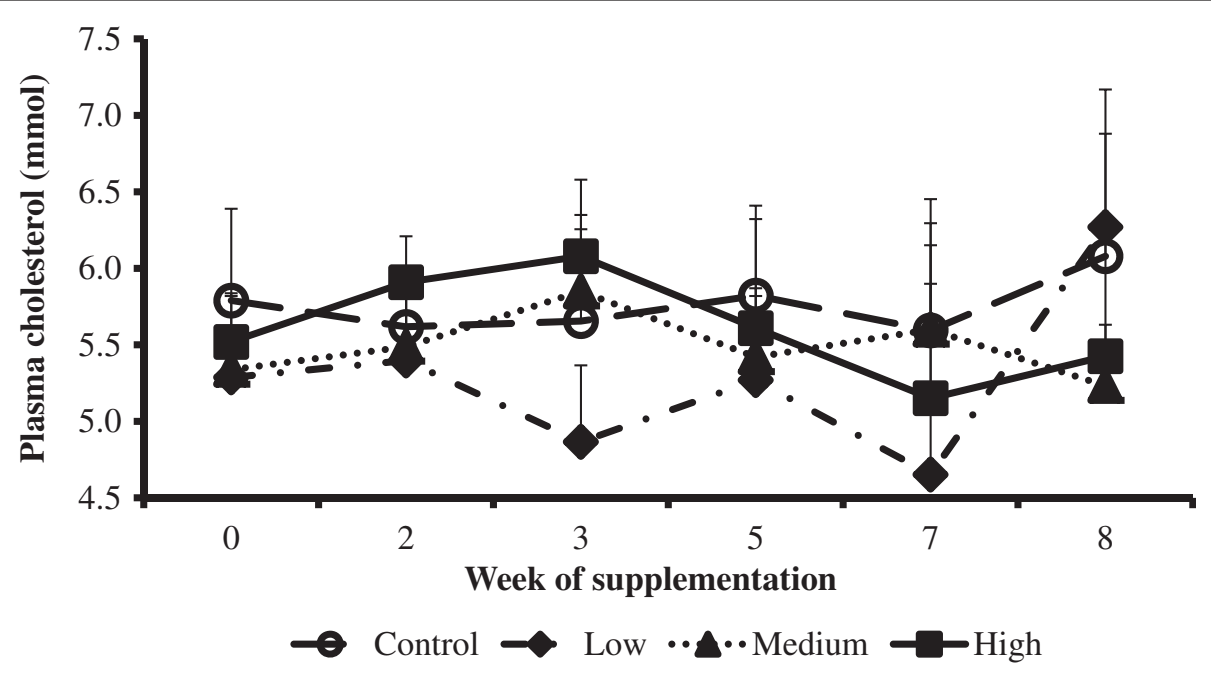

Figure 3 Interaction between CDCO supplementation level and week of supplementation on plasma concentrations of cholesterol. Error bars ( \pm SEM). Week 0, week before fat supplementation, week 1, when fat supplementation commenced. 


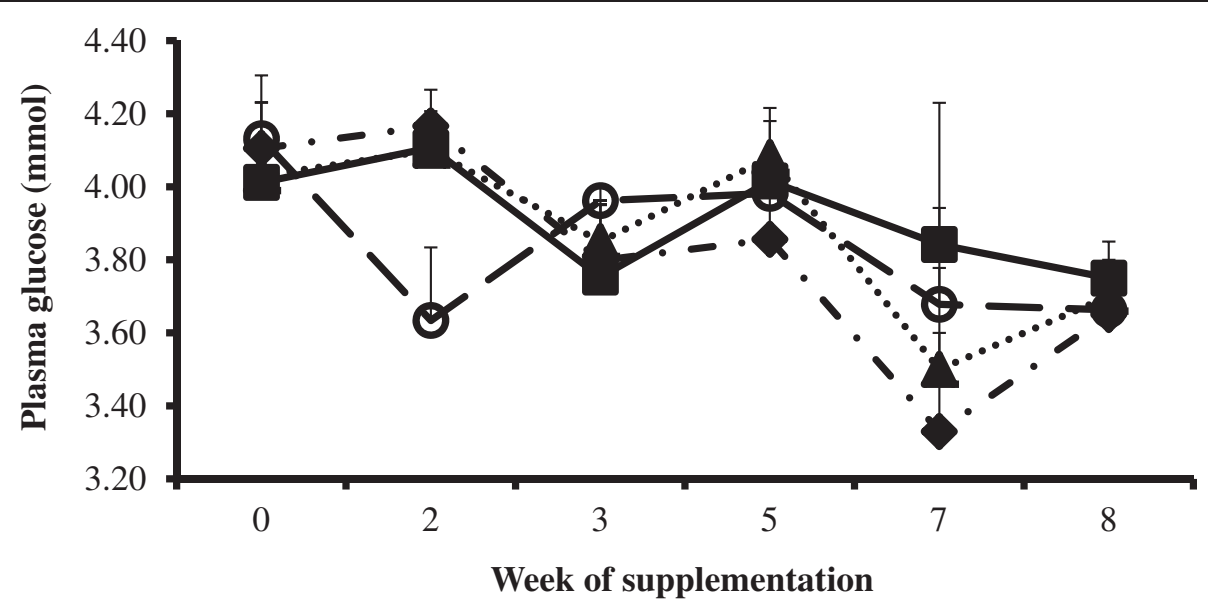

$\rightarrow$ Control $\rightarrow$ Low $\cdot . \cdot \cdot$ Medium $\rightarrow$ High

Figure 4 Interaction between CDCO supplementation level and week of supplementation on plasma concentrations of glucose. Error bars $( \pm$ SEM). Week 0 , week before fat supplementation, week 1 , when fat supplementation commenced.

coinciding with the early lactation phase, while in their study, the cows were 300 days in milk almost at the end of their lactation. Another major area of difference between the two studies lies in the type of fat fed. While we supplemented the cows with crude degummed canola, they fed an inert fat that is rumen-protected. The effect of fat supplementation on plasma BHBA has been associated with the availability of carbohydrates [31] and the impact of long chain fatty acids (particularly Docosahexaenoic acid, C22:6) on hepatic gluconeogenesis [32]. It would thus appear that in our study, as the level of CDCO supplementation increased, hepatic gluconeogenesis also increased due to a likely influx of available dietary carbohydrates and docosahexaenoic acid.
Cholesterol contains lipoproteins and the high and low density lipoproteins [33-35], which are all precursors for progesterone metabolism [35]. Progesterone is one of the hormones essential for fertility in cows. Fat supplements have been used efficiently to alter the plasma cholesterol concentration of dairy cows $[36,37]$. However, in the current study, dietary fat did not influence plasma cholesterol concentration. This can partly be explained by the fact that canola is known to contain mainly phytosterol [38,39]. Phytosterol contains low levels of cholesterol [38]. Previous studies have also reported that phytosterol can significantly reduce cholesterol in humans with hypercholesterolemic condition [40]. Therefore, the lack of significant effect observed in

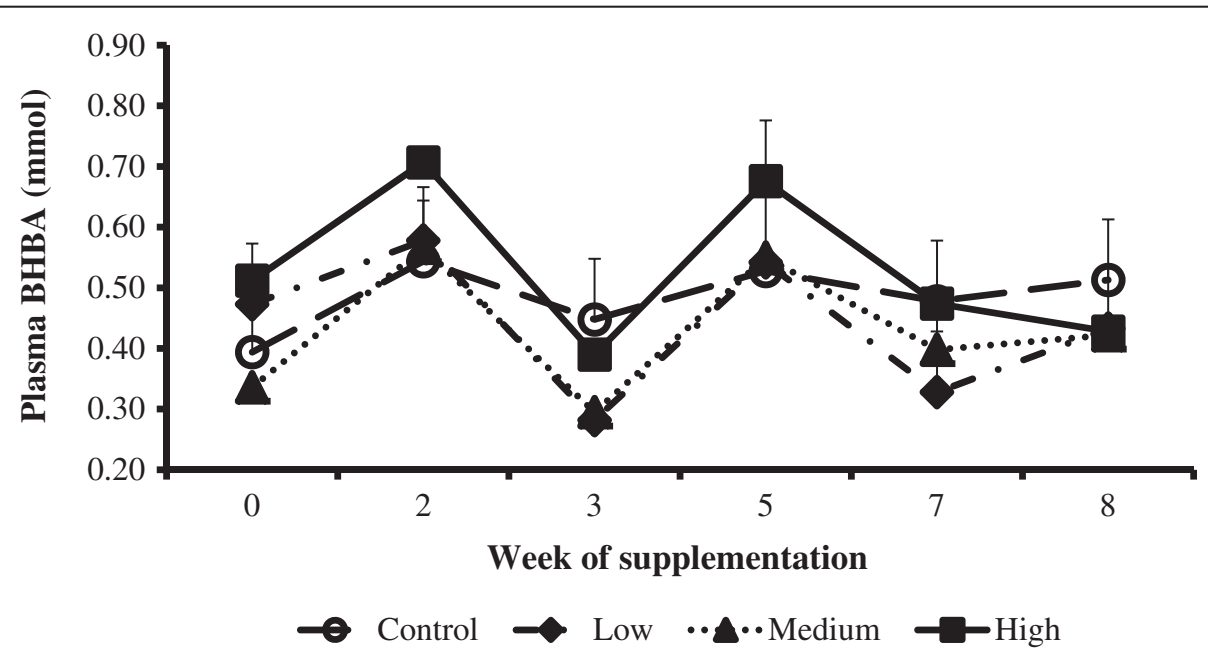

Figure 5 Interaction between CDCO supplementation level and week of supplementation on plasma concentrations of $\beta$-hydroxybutyrate. Error bars ( \pm SEM). Week 0 , week before fat supplementation, week 1 , when fat supplementation commenced. 
the present study could be explained by the hypocholesterolemic effect of CDCO.

The demand for glucose rises sharply post-partum due to increased energy requirements for lactation [7]. However, due to low dry matter intake after parturition, the amount of glucose produced is not enough to support the cow's lactation requirements. Ruminal propionate produced during ruminal fermentation is used as a substrate in the gluconeogenesis pathway to produce glucose [41-43]. The effect of dietary fat supplements on plasma glucose has been associated with their ability to provide adequate rumen propionate $[42,43]$. In the current study, there were no significant differences between CDCOsupplemented and unsupplemented cows. The lack of significance in the present result indicates that the dietary fat treatment supplied adequate propionate to the rumen to affect plasma glucose concentration. Additionally, the effect of biohydrogenation of unprotected supplementary fat in the rumen was not any different between supplemented and control group of cows [44,45], hence the availability and levels of substrates necessary for glucose metabolism were similar in all cows.

Week of supplementation had a significant influence on NEFA, BHBA and glucose. This seems to suggest that the longer cows are supplemented with $\mathrm{CDCO}$, the greater the impact on plasma metabolite profiles. The negative correlation between NEFA and cholesterol, and the positive correlation between cholesterol and glucose in the present study corroborate the theory that negative energy balance can impact negatively on production parameters in a pasture based setting.

When plasma glucose levels decrease, body fat remobilization is instigated from nutrient accrual to provide sufficient energy that can maintain continuous milk production until the animal returns to a positive energy balance. It has been found that cows suffering from negative energy balance have increased concentrations of serum glucagon and growth hormones, whereas the concentrations of insulin and insulin growth factor-I are decreased. Some proposed theories postulate that dietary fat supplement favours lower blood NEFA concentration by providing extra energy postpartum. Other research findings indicate that feeding dairy cows with fat supplements could promote increased insulin production because of the amount of increased energy provided through the production of acetate, propionate and butyrate (precursors for glucose, fat and carbohydrate production). However, studies investigating the response of plasma insulin to fat supplementation are inconsistent. For instance, some studies reported decreased plasma concentrations of insulin, while others reported steady insulin increases postpartum in cows fed six different diets containing fats. Therefore the mechanism of fat supplementation and relationship with insulin production is still poorly understood and warrants further elucidation.

\section{Conclusions}

Canola supplements are effective dietary energy sources because they are involved in the production of volatile fatty acids which serve as lipid metabolic substrates for the synthesis of glucose, fats and carbohydrates for lactation. The concentrations of plasma NEFA, BHBA and glucose are indicators for gauging the energy balance status of a lactating cow. Week of supplementation was a more significant factor than level of CDCO supplementation in influencing plasma metabolite profiles, thus suggesting that the duration of supplementation with CDCO has a greater impact on all the plasma metabolites investigated in this study. It was also apparent from this study that primiparous cows grazing high quality pasture at about 40 days in milk (DIM), had adequate energy intake to overcome any extreme negative energy balance scenario at this stage of lactation. It also implies that fat supplementation may not be necessary in spring when there is abundant and lush pasture, but may be needed during winter or summer when pasture is scanty to boost the energy intake of cows. The hypothesis that feeding grazing primiparous Holstein-Friesian cows for eight weeks with incremental levels of CDCO supplement will decrease plasma non-esterified fatty acid (NEFA) and $\beta$-hydroxybutyrate (BHBA), but increase plasma cholesterol and glucose metabolites does not hold true and should be rejected. Therefore, it is concluded that primiparous Holstein-Friesian dairy cows in a pasture-based setting have enough energy intakes from grass in spring to maintain adequate production and reproduction performances. However, there is the need for further investigation into the interaction between circulating plasma hormones and gene expression profiles of supplemented cows to provide a better understanding of CDCO's role in future applications as a dietary fat supplement for lactating cows.

\section{Methods}

\section{Site and climatic conditions}

All experimental procedures were in accordance with the University of Tasmania Animal Ethics Committee guidelines (Animal Ethics Permit Number A0012583), the 1993 Tasmania Animal Welfare Act and the 2004 Australian Code of Practice for the Care and Use of Animals for Scientific Purposes. The experiment was carried out at the University of Tasmania's Dairy Research Centre, Tasmanian Institute of Agriculture (TIA) Elliot Dairy Research Farm in Somerset, North-Western Tasmania, Australia, from September to November 2012. Tasmania is Australia's smallest state with a land size of 68,000 square kilometers and located within the cool, temperate, climatic zone at latitude $42^{\circ}$ South and longitude $147^{\circ}$ East. It is characterized by four distinct seasons - winter, autumn, spring and summer. The experiment 
was carried out in spring when the annual rainfall was $2500 \mathrm{~mm}$ and humidity was approximately $60 \%$.

\section{Animals and treatments}

The condition and energy status of the experimental cows was visually assessed based on body condition score (BCS) on a scale of $1-5[46,47]$, the cows were in negative energy balance. Twenty primiparous, springcalving, purebred, Holstein-Friesian cows (average liveweight of $400 \pm 40 \mathrm{Kg}$, BCS $4 \pm 1,40 \pm 8$ days in milk (DIM) early lactation phase; and daily milk yield of 20.7 litres), were randomly allocated into 1 of 4 treatments of CDCO $(25 \mathrm{ml} / \mathrm{KgDM}, 35 \mathrm{ml} / \mathrm{KgDM}$ and $50 \mathrm{ml} /$ $\mathrm{KgDM}$ ) and the control (no CDCO- $0 \mathrm{ml} / \mathrm{KgDM}$ ). This replicated herd of cows ( $\mathrm{n}=5$ per treatment group) receiving $\mathrm{CDCO}$ supplements was placed under the same management and rotated in electric fenced paddocks with the Control cows offered wheat-based pellets without CDCO. Together, the animals had access to $3000 \mathrm{~kg}$ DM of forages, a mixture of ryegrass (Lolium perenne), cocksfoot (Dactylis glomerata), and white clover (Trifolium repens) pasture grazed at the two-leaf stage. Water was offered at ad libitum. The treated cows grazed the same pasture allotment as the Control cows but were offered CDCO plus wheat-based pellet at the rate of $50 \mathrm{ml} / \mathrm{KgDM}$ (for the high level of supplementation group), $35 \mathrm{ml} / \mathrm{KgDM}$ (medium level of supplementation group) and $25 \mathrm{ml} / \mathrm{KgDM}$ (low level of supplementation group). The current level of CDCO was calculated based on $7 \%$ total fat allowed in the diet of grazing cows [9] and the physiological status of being in the early lactation phase. Each cow received $6 \mathrm{~kg}$ of the pelleted supplements daily for eight weeks, after two weeks of adjustment. Supplements were offered to cows in two splits; morning $(3 \mathrm{~kg})$ and evening $(3 \mathrm{~kg})$ milking sessions at $0500 \mathrm{~h}$ and $1500 \mathrm{~h}$. There was no feed residual left over from any of the groups. The exact pasture intake was difficult to estimate as the case is under grazing conditions. The chemical compositions of the treatment, control and basal feeds are presented in Table 4.

\section{Feed chemical composition and analysis}

Dry matter (DM) content of the basal and experimental diets was determined by drying samples to a constant temperature at $65^{\circ} \mathrm{C}$ in a fan forced oven, finely ground to pass through a $2 \mathrm{~mm}$ sieve using Laboratory Mill ('Thomas Model 4 Wiley Mill; Thomas Scientific), and further drying at $105^{\circ} \mathrm{C}$ for $24 \mathrm{~h}$. The DM was computed as the difference between the initial and final weights of samples expressed as a percentage. Moisture content was determined by subtracting the\% DM from $100 \%$. Ash content was determined by combusting samples in a furnace at $600^{\circ} \mathrm{C}$ for 8 hours. Neutral detergent (NDF) and acid detergent fiber (ADF) contents were measured using an Ankom fiber analyzer, ${ }^{\mathrm{b}} \mathrm{ANKOM}{ }^{220}$; ANKOM Technology, USA [48]. The analysis for total nitrogen was determined using a ${ }^{\circ}$ Thermo Finnigan EA 1112 Series Flash Elemental Analyzer [49] and the values multiplied by 6.25 to give the crude protein $(\mathrm{CP})$ percentage. Ether extract $(\mathrm{EE})$ was determined using an Ankom fat/oil extractor ( ${ }^{\mathrm{d}} \mathrm{ANKOM}^{\mathrm{XT} 15}$; ANKOM Technology, USA) based on hexane-petroleum ether solvent extraction. Metabolisable energy (ME) was calculated as per Weiss [50].

\section{Blood sample collection and plasma metabolite analysis} Blood samples $(10 \mathrm{ml})$ were collected from each experimental cow after the morning milking $(0500 \mathrm{~h})$ on week zero and fortnightly thereafter, until the end of the experiment. All samples were collected by coccygeal venipuncture into heparin vacutainers. All collected blood samples were centrifuged at $1,125 \mathrm{X} \mathrm{g}$ for 10 minutes at $4^{\circ} \mathrm{C}$ to facilitate distinct separation between the plasma and serum. The plasma fractions were decanted into $2 \mathrm{ml}$ vials, sealed with an airtight cap and stored at $-20^{\circ} \mathrm{C}$ until further laboratory analyses. Plasma NEFA, BHBA, cholesterol and glucose

Table 4 Chemical composition of feed components

\begin{tabular}{llll}
\hline Component (\%DM) & \multicolumn{2}{l}{ Feed components } & Basal diet (Pasture) \\
\cline { 2 - 4 } & Treatment feed (canola oil) & Control feed (No canola oil) & 55.0 \\
\hline MC & 8.2 & 9.1 & 94.5 \\
DM & 91.8 & 90.9 & 27.7 \\
ADF & 8.0 & 9.0 & 45.9 \\
NDF & 20.0 & 21.1 & 3.0 \\
EE & 6.2 & 2.1 & 9.3 \\
Ash & 9.7 & 8.9 & 23.9 \\
NFC & 52.8 & 59.0 & 21.0 \\
CP & 12.7 & 10.4 & 3999.2 \\
ME (K/100gDM) & 4083.3 & 4065.7 & \\
\hline
\end{tabular}

All feeds were analyzed on a dry weight basis; Moisture content (MC), Dry matter (DM), organic matter (OM), neutral detergent fiber (NDF), acid detergent fiber (ADF), non-fibrous carbohydrate (NFC), ether extract (EE), crude protein (CP) and metabolisable energy (ME). 
samples were commercially analysed at the Animal Health Laboratories, Department of Agriculture and Food (South Perth, Australia) using appropriate kits (ACS-ACOD Method) from Wako Pure Chemical Industries Ltd (Code No. 279-75401) on ${ }^{\mathrm{e} B e c k m a n}$ Coulter (AU 400) analyzer.

\section{Statistical analysis}

Initially, summary statistics by level and week of CDCO supplementation were computed to give means, standard deviations standard error, variance, minimum and maximum values that were scrutinised for any data entry errors. Testing for linear, quadratic and cubic orthogonal contrasts by regressing the dependent on explanatory variables was carried out using PROC REG (SAS 2009). Subsequently, NEFA, BHBA, glucose and cholesterol were analysed by repeated measures analysis of variance using PROC MIXED (SAS , 2009) utilising compound symmetry covariance structure and week of supplementation as the repeated effect. The model included treatment, week of lactation and interaction between treatment and week of lactation as fixed effects, while base line milk values and cows were fitted as random effects and the degrees of freedom were estimated by the Satterthwaite method (SAS, 2009). Variables of interest having significant treatment and or week of lactation effects are presented in Tables and Figures as pooled Least Squares Means and Standard Error of Means (LSM \pm SEM) and differences between means were considered significant at the $P<0.05$ threshold unless otherwise stated. Significant differences and mean separations were carried out using Tukey's probability pairwise comparison tests (SAS, 2009). Pearson correlation coefficients between dependent variables were estimated using PROC CORR (SAS, 2009) with significance determined using Bonferroni's probability pairwise comparison test (SAS, 2009). Correlation analyses were initially carried out on the whole data set and also by week of supplementation, but the weekly correlation values were dropped and those from the whole data retained because there were no significant differences between the two sets of values.

\section{Endnotes}

${ }^{a}$ Thomas Model 4 Wiley Mill; Thomas Scientific.

${ }^{\mathrm{b}} \mathrm{ANKOM}^{220}$; ANKOM Technology, USA.

${ }^{\mathrm{c}}$ Thermo Finnigan EA 1112 Series Flash Elemental Analyzer.

${ }^{\mathrm{d}} \mathrm{ANKOM}{ }^{\mathrm{XT15}}$; ANKOM Technology, USA.

${ }^{\mathrm{e}}$ Beckman Coulter (AU 400) analyzer.

\section{Abbreviations}

ADF: Acid detergent fiber; BHBA: $\beta$-Hydroxybutyrate; CDCO: Crude degummed canola oil; CP: Crude protein; DM: Dry matter; EE: Ether extract; ME: Metabolisable energy; MC: Moisture content; NEBAL: Negative energy balance; NDF: Neutral detergent fiber; NEFA: Non-esterified fatty acids; NFC: Non-fibrous carbohydrate; OM: Organic matter; SAS: Statistical analysis software.

\section{Competing interests}

The authors declare that they have no competing interests.

\section{Authors' contributions}

This work was carried out in collaboration between all authors. Author JRO researched and wrote the first draft of the manuscript as part of his PhD project, carried out the experiment, collected samples and performed feed chemical analysis. Authors BSMA, ROB, PN and AEOMA conceived the research idea, experimental design, reading and making needed changes to the draft and final manuscript as a research article. All authors read and approved the final manuscript.

\section{Acknowledgements}

This study was supported with grants from the University of Tasmania Graduate Research Scholarship and Postgraduate Top-up scholarships from the Tasmanian Institute of Agriculture. We also acknowledge the field advisory role of Mark Freeman, academic advisory roles of Peter Nichols and Peter Lane, collaborative research support from Coprice Pty Limited, Cobden, Victoria, and TasHerd Pty Limited, Hadspen, Tasmania, Australia.

\section{Author details}

${ }^{1}$ Animal Science and Genetics, Tasmanian Institute of Agriculture, School of Land and Food, Faculty of Science, Engineering \& Technology, University of Tasmania, Private Bag 54, Hobart, TAS 7001, Australia. ${ }^{2}$ College of Medicine and Dentistry, Division of Tropical Health and Medicine, James Cook University, Townsville, Queensland 4871, Australia. ${ }^{3}$ CopRice Feeds, PO Box 104, Cobden, Victoria 3266, Australia. ${ }^{4}$ TasHerd Pty Limited, P. O. Box 68, Hadspen, Tasmania 7290, Australia. ${ }^{5}$ Veterinary and Biomedical Sciences, College of Public Health, Medical and Veterinary Sciences, Division of Tropical Health and Medicine, James Cook University, Townsville, Queensland 4811, Australia.

Received: 30 May 2014 Accepted: 18 September 2014 Published online: 26 September 2014

\section{References}

1. Moran J, McLean D: Heifer Rearing: A Guide to Rearing Dairy Replacement Heifers in Australia. Victoria: Bolwarrah Press; 2001.

2. Bauman DE, Griinari JM: Regulation and nutritional manipulation of milk fat: low-fat milk syndrome. Livest Prod Sci 2001, 70:15-29.

3. Colazo M, Hayirli A, Doepel L, Ambrose D: Reproductive performance of dairy cows is influenced by prepartum feed restriction and dietary fatty acid source. J Dairy Sci 2009, 92:2562-2571.

4. Grummer R, Carroll D: Effects of dietary fat on metabolic disorders and reproductive performance of dairy cattle. J Anim Sci 1991, 69:3838-3852.

5. Leroy JLMR, Vanholder T, Mateusen B, Christophe A, Opsomer G, de Kruif A, Genicot G, Van Soom A: Non-esterified fatty acids in follicular fluid of dairy cows and their effect on developmental capacity of bovine oocytes in vitro. Reproduction 2005, 130:485-495.

6. Lopes C, Cooke R, Reis M, Peres R, Vasconcelos J: Strategic supplementation of calcium salts of polyunsaturated fatty acids to enhance reproductive performance of Bos indicus beef cows. J Anim Sci 2011, 89:3116-3124.

7. Drackley JK, Overton TR, Douglas GN: Adaptations of glucose and long-chain fatty acid metabolism in liver of dairy cows during the periparturient period. J Dairy Sci 2001, 84:100-112.

8. Adewuyi A, Gruys E, Van Eerdenburg F: Non-esterified fatty acids (NEFA) in dairy cattle. A review Vet Quart 2005, 27:117-126.

9. Schroeder G, Gagliostro G, Bargo F, Delahoy J, Muller L: Effects of fat supplementation on milk production and composition by dairy cows on pasture: a review. Livest Prod Sci 2004, 86:1-18.

10. Delbecchi L, Ahnadi C, Kennelly J, Lacasse P: Milk fatty acid composition and mammary lipid metabolism in Holstein cows fed protected or unprotected canola seeds. J Dairy Sci 2001, 84:1375-1381.

11. Hayirli A, Keisler DH, Doepel L: Peripartum responses of dairy cows to prepartal feeding level and dietary fatty acid source. J Dairy Sci 2011, 94:917-930.

12. Khorasani G, De Boer G, Robinson P, Kennelly J: Effect of canola fat on ruminal and total tract digestion, plasma hormones, and metabolites in lactating dairy cows. J Dairy Sci 1992, 75:492-501. 
13. Khorasani GR, Kennelly Jj: Effect of added dietary fat on performance, rumen characteristics, and plasma metabolites of mid-lactation dairy cows. J Dairy Sci 1998, 81:2459-2468.

14. Bellows R, Grings E, Simms D, Geary T, Bergman J: Effects of feeding supplemental fat during gestation to first-calf beef heifers. Prof Anim SCi 2001, 17:81-89.

15. Bottger J, Hess B, Alexander B, Hixon D, Woodard L, Funston R, Hallford D, Moss $\mathrm{G}$ : Effects of supplementation with high linoleic or oleic cracked safflower seeds on postpartum reproduction and calf performance of primiparous beef heifers. J Anim Sci 2002, 80:2023-2030

16. Chelikani PK, Glimm DR, Keisler DH, Kennelly JJ: Effects of feeding or abomasal infusion of canola oil in Holstein cows. 2. Gene expression and plasma concentrations of cholecystokinin and leptin. J Dairy Res 2004, 71:288-296.

17. Chichlowski MW, Schroeder JW, Park CS, Keller WL, Schimek DE: Altering the fatty acids in milk fat by including canola seed in dairy cattle diets. J Dairy Sci 2005, 88:3084-3094.

18. LaCount D, Drackley J, Laesch S, Clark J: Secretion of oleic acid in milk fat in response to abomasal infusions of canola or high oleic sunflower fatty acids. J Dairy Sci 1994, 77:1372-1385.

19. Beam S, Butler W: Energy balance, metabolic hormones, and early postpartum follicular development in dairy cows fed prilled lipid. J Dairy Sci 1998, 81:121-131.

20. Butler W: Nutritional interactions with reproductive performance in dairy cattle. Anim Reprod Sci 2000, 60:449-457.

21. Butler W: Energy balance relationships with follicular development, ovulation and fertility in postpartum dairy cows. Livest Prod Sci 2003, 83:211-218.

22. De Vries MC, Veerkamp R: Energy balance of dairy cattle in relation to milk production variables and fertility. J Dairy Sci 2000, 83:62-69.

23. Andersen JB, Ridder $C$, Larsen T: Priming the cow for mobilisation in the peri-parturient period: effects of supplementing the dry cow with saturated fat or linseed. J Dairy Sci 2008, 91:1029-1043.

24. Douglas G, Rehage J, Beaulieu A, Bahaa A, Drackley J: Prepartum nutrition alters fatty acid composition in plasma, adipose tissue, and liver lipids of periparturient dairy cows. J Dairy Sci 2007, 90:2941-2959.

25. Drackley JK: Biology of dairy cows during the transition period: the final frontier? J Dairy Sci 1999, 82:2259-2273.

26. Wathes D, Bourne N, Cheng Z, Mann G, Taylor V, Coffey M: Multiple correlation analyses of metabolic and endocrine profiles with fertility in primiparous and multiparous cows. J Dairy Sci 2007, 90:1310-1325.

27. Meikle A, Kulcsar M, Chilliard Y, Febel H, Delavaud C, Cavestany D, Chilibroste P: Effects of parity and body condition at parturition on endocrine and reproductive parameters of the cow. Reproduction 2004, 127:727-737.

28. Heitmann R, Fernandez J: Autoregulation of alimentary and hepatic ketogenesis in sheep. J Dairy Sci 1986, 69:1270-1281.

29. Roche J, Sheahan A, Chagas L, Boston R: Short communication: change in Plasma Ghrelin in dairy cows following an intravenous glucose challenge. J Dairy Sci 2008, 91:1005-1010.

30. Duske $\mathrm{K}$, Hammon $\mathrm{H}$, Langhof AK, Bellmann O, Losand B, Nürnberg $\mathrm{K}$ Nürnberg G, Sauerwein $H$, Seyfert $H$, Metges C: Metabolism and lactation performance in dairy cows fed a diet containing rumen-protected fat during the last twelve weeks of gestation. J Dairy Sci 2009, 92:1670-1684

31. Sutton J: Digestion and absorption of energy substrates in the lactating cow. J Dairy Sci 1985, 68:3376-3393.

32. Mashek D, Grummer R: Effects of long chain fatty acids on lipid and glucose metabolism in monolayer cultures of bovine hepatocytes. J Dairy Sci 2003, 86:2390-2396

33. Bauchart D: Lipid absorption and transport in ruminants. J Dairy Sci 1993, 76:3864-3881.

34. Grummer R, Carroll D: A review of lipoprotein cholesterol metabolism: importance to ovarian function. J Anim Sci 1988, 66:3160.

35. Staples C, Burke J, Thatcher W: Influence of supplemental fats on reproductive tissues and performance of lactating cows. J Dairy Sci 1998, 81:856-871.

36. Carroll D, Jerred M, Grummer R, Combs D, Pierson R, Hauser E: Effects of fat supplementation and immature alfalfa to concentrate ratio on plasma progesterone, energy balance, and reproductive traits of dairy cattle. J Dairy Sci 1990, 73:2855-2863.
37. Hawkins D, Niswender K, Oss G, Moeller C, Odde K, Sawyer H, Niswender G: An increase in serum lipids increases luteal lipid content and alters the disappearance rate of progesterone in cows. J Anim Sci 1995, 73:541-545.

38. Hamama AA, Bhardwaj HL, Starner DE: Genotype and growing location effects on phytosterols in canola oil. J Am Oil Chem Soc 2003, 80:1121-1126.

39. Vlahakis $C$, Hazebroek J: Phytosterol accumulation in canola, sunflower, and soybean oils: effects of genetics, planting location, and temperature. J Am Oil Chem Soc 2000, 77:49-53.

40. Miettinen TA, Puska P, Gylling H, Vanhanen $H$, Vartiainen E: Reduction of serum cholesterol with sitostanol-ester margarine in a mildly hypercholesterolemic population. New Engl J Med 1995, 333:1308-1312

41. Funston RN: Fat supplementation and reproduction in beef females. J Anim Sci 2004, 82:154-161.

42. Howlett CM, Vanzant E, Anderson L, Burris W, Fieser B, Bapst R: Effect of supplemental nutrient source on heifer growth and reproductive performance, and on utilization of corn silage-based diets by beef steers. J Anim Sci 2003, 81:2367-2378.

43. Williams G, Stanko R: Dietary fats as reproductive nutraceuticals in beef cattle. 1999.

44. Chilliard Y, Glasser F, Ferlay A, Bernard L, Rouel J, Doreau M: Diet, rumen biohydrogenation and nutritional quality of cow and goat milk fat. Eur J Lipid Sci Tech 2007, 109:828-855.

45. Jenkins T: Lipid metabolism in the rumen. J Dairy Sci 1993, 76:3851-3863.

46. Stockdale CR: Body condition at calving and the performance of dairy cows in early lactation under Australian conditions: a review. Aust J Exp Agr 2001, 41:823-839.

47. DPI: The Condition Magician. Body Condition Scoring in Dairy Herds. Seasonal/ Split and Year Round Calving. Victoria: Department of Primary Industry; 2003.

48. Van Soest PV, Robertson J, Lewis B: Method for dietary fibre, neutral detergent fibre, and non-starch polysaccharides in relation to animal nutrition. J Dairy Sci 1991, 74:3583-3597.

49. Del Galdo I, Oechel WC, Francesca Cotrufo M: Effects of past, present and future atmospheric $\mathrm{CO}_{2}$ concentrations on soil organic matter dynamics in a chaparral ecosystem. Soil Biol Biochem 2006, 38:3235-3244.

50. Weiss WP: Predicting energy values of feeds 1. J Dairy Sci 1993, 76:1802-1811

\section{doi:10.1186/s12917-014-0224-5}

Cite this article as: Otto et al: Effect of crude degummed canola oil and ad libitum grazing on plasma metabolites of primiparous HolsteinFriesian cows in a pasture-based system. BMC Veterinary Research 2014 10:224.

\section{Submit your next manuscript to BioMed Central and take full advantage of:}

- Convenient online submission

- Thorough peer review

- No space constraints or color figure charges

- Immediate publication on acceptance

- Inclusion in PubMed, CAS, Scopus and Google Scholar

- Research which is freely available for redistribution 